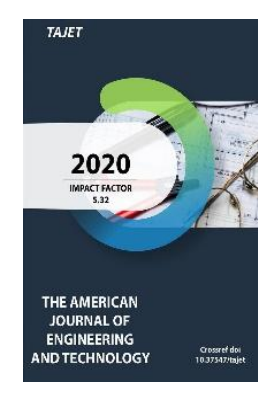

Journal Website: http://usajournalshub.c om/index,php/tajet

Copyright: Original content from this work may be used under the terms of the creative commons attributes 4.0 licence.

\section{Drying Precess-A Factor That Ensures Long-Term Storage Of Agricultural Raw Materials}

\author{
Akabirov Laziz Isamidinov \\ Scientific Candidate Of The Bukhara Institute Of Engineering And Technology, Bukhara, \\ Uzbekistan \\ Gafurov Karim Hakimovich \\ Candidate Of Technical Sciences, Associate Professor, Bukhara Institute Of Engineering And \\ Technology, Bukhara, Uzbekistan \\ Majidov Kakhramon Halimovich \\ Doctor Of Technical Sciences, Professor, Bukhara Institute Of Engineering And Technology, \\ Bukhara, Uzbekistan
}

\title{
ABSTRACT
}

It is shown that the main factors providing the processes of drying agricultural raw materials are thermophysical properties and dimensions, the shape and condition of the outer surface, the interval of changes in the moisture content of the material during the drying process, etc. The internal structure of the material has the strongest effect on the drying process. For dispersed materials with particles with a diameter of more than $2 \mathrm{~mm}$ and a critical pore radius of less than $2 \mathrm{~nm}$, the duration of convective drying is more than $1 \mathrm{~h}$, while for dispersed materials with a critical pore radius of more than $100 \mathrm{~nm}$ (all other things being equal) it is within $0.5-3 \mathrm{p}$.

\section{KEYWORDS}

Agricultural raw materials, drying processes, storage duration, mathematical methods.

\section{INTRODUCTION}

The main goal of the food industry is to supply the population with high-quality natural food [1-3].
Vegetables and fruits should be present in the human diet all year round, as an irreplaceable source 
of vitamins, organic acids, minerals, necessary for the full life of people. Therefore, storage and processing of plant materials with the preservation of all their nutritional properties is the main task of the food and processing industry.

The powder method is the most promising, efficient and compact method for long-term storage without loss and transportation of plant raw materials [4-6].

The existing methods for producing food powders are cumbersome in hardware, energy-intensive, and time-consuming; therefore, the problem of creating new highly efficient technologies for processing plant raw materials is an urgent task for the food industry.

The purpose of the work is to study the process of drying agricultural raw materials and ensure the duration of their storage.

Research objects. Agricultural raw materials, drying processes, storage duration, chemical composition, quality indicators.

Research methods. Physical, chemical physicochemical, biological

\section{RESULTS AND DISCUSSION}

When classifying materials as objects of drying, one cannot proceed only from the assessment of the behavior of the material in that other (even typical, and even less typical) drying apparatus. The classification should reflect the results of a comprehensive analysis of the material as an object of drying and include no more than three four generalized indicators, of which one (dominant) determines the class (group) of the material according to this classification, and the rest - a subgroup and category [7-9].

On the basis of the proposed classification, it is possible to carry out the transition from statics to the kinetics of drying, using the principle of corresponding states. Knowing the kinetics of drying of characteristic representatives of each group under conditions close to optimal, as well as the rate of moisture removal from the pores of different groups, it is possible to calculate and build by the material belonging to this other group and the characteristics of the pore space (distribution of pores by diameters, pore volume of different diameters) the curve of the kinetics of drying this material in conditions close to optimal, and choose a rational type of apparatus, as well as an active hydrodynamic regime.

As you know, drying is a very complex technological process that depends on a large number of factors, knowledge of which is essential for the analysis and calculation of the process [10-11]. In all cases, drying removes (in the form of vapor or liquid) a highly volatile component (water, organic solvent).

The moisture content of the body $U$ is the ratio of the mass of moisture $\mathrm{W}$ contained in the body to the mass of the dry body $G$

$$
U=W / G
$$

When describing practical issues of drying, they usually use the concept of body moisture $\omega$

$$
\omega=\frac{W}{W+G}
$$

relations (1) and (2) it follows

$$
\omega=\frac{U}{1+U}
$$

At low values of the moisture content $(U \ll 1)$, the value $(1+U)$ in $(3)$ is almost equal to unity, and the moisture content of the body is almost the same as its moisture content.

In the process of drying, a wet body tends to a state of equilibrium with the environment, therefore, the moisture content of the body $\mathrm{U}$ and its temperature 
$T$ depend on time $\tau$ and on the coordinates of the point of the body $x 1, x 2, \times 3$

$$
\begin{aligned}
& U=U\left(x_{1}, x_{2}, x_{3}, \tau\right) \\
& T=T\left(x_{1}, x_{2}, x_{3}, \tau\right)
\end{aligned}
$$

The dependence of temperature on time can be ignored, the body temperature becomes equilibrium much faster, moisture content. Dependences (4) and (5) describe the dynamics of drying and heating of the body. The change in time of the average volume of the body moisture-containing $U$ and temperatures $\mathrm{T}$ characterizes the kinetics of drying and heating processes.

$$
\begin{aligned}
& \bar{U}=\bar{U}(\tau) \\
& \bar{T}=\bar{T}(\tau) \\
& \bar{U}=\iint_{V} \int U\left(x_{1}, x_{2}, x_{3}, \tau\right) d x_{1} d x_{2} d x_{3} \\
& \bar{T}=\iiint_{V} T\left(x_{1}, x_{2}, x_{3}, \tau\right) d x_{1} d x_{2} d x_{3}
\end{aligned}
$$

The rate of drying is determined by the rate of drying, which decreases as equilibrium is approached and usually tends to zero. The intensity of drying depends on a number of factors that indicate the complexity of the actual drying process, especially in production conditions, and the difficulty of obtaining an adequate mathematical description for it. The factors that determine the dried material as a drying object have the greatest influence on the drying process. They characterize the resistance of the material to the transfer of moisture inside it and from its surface into the environment, the strength of the connection between moisture and the material, the ability of the material to perceive the heat supplied to it.

These factors include the internal structure of the material, its thermophysical properties and dimensions, the shape and condition of the external surface, the range of changes in the moisture content of the material during the drying process, etc. The internal structure of the material has the strongest effect on the drying process. For dispersed materials with particles with a diameter of more than $2 \mathrm{~mm}$ and a critical pore radius of less than $2 \mathrm{~nm}$, the duration of convective drying is more than $1 \mathrm{~h}$, while for dispersed materials with a critical pore radius of more than $100 \mathrm{~nm}$ (all other things being equal) it is within $0.5-3 p$.

In the process of drying materials with very small particles or a surface with a large number of sharp projections with a small radius of curvature, an additional flow of moisture appears from the material to the drying agent. This is due to an increase in the saturated vapor pressure above the convex surface. According to the Thomson - Kelvin formula [12], such an increase is noticeable for very small radii of curvature of the surface

$$
(\mathrm{r}<\mathrm{m}) \text { and is equal to } p_{\text {son }}-p_{0}=p_{0}\left[\exp \left(\frac{M \sigma K}{\rho_{\text {K }} R T}\right)-1\right]
$$

where, - respectively, the saturated vapor pressure over the convex and flat surfaces; $K$ is the average curvature of the surface; $K=1 / R 1+1 / R 2$ are the main radii of curvature of the interface; $M$ is the molar mass of the substance; a - coefficient of surface tension; hw - raft- fluidity; $\mathrm{R}$ is the universal gas constant; $\mathrm{T}$ - absolute temperature.

The parameters of the drying agent (heat carrier) have a significant effect on the drying process: temperature $t$, relative humidity (relative pressure), 
speed of movement relative to the material $v$, pressure $p$.

Using a simplified mathematical model as an example, we will consider the effect of the parameters of the drying agent on the drying rate. Let us assume that all the heat supplied to a spherical

$$
\alpha \pi d^{2} f(t-\theta)=N \frac{\pi d^{3}}{6} \rho_{M} r_{\Pi}
$$

where

$$
N=\frac{6 \alpha f(t-\theta)}{\rho_{M} d r_{\Pi}}
$$

where $\mathrm{o}$ is the coefficient of heat transfer from the coolant to the material particle; / Is the form factor; $d$ - $r$ is the diameter of the material particle; $p$ is the density of the material, cha; ha is the heat of vaporization; 6 -material temperature.

It follows from the equation that the drying rate increases with a decrease in the particle size of the material to be dried, an increase in the temperature of the coolant and the rate of heat supply to the material, which is characterized by the heat transfer coefficient. It should be noted that, in turn, also depends on $d$ and weaker on $t$. For a number of correlations, for example, for the Fresling correlation, the heat transfer coefficient is proportional to and. particle of material goes to the evaporation of the moisture it contains; the particle of the material is small, and therefore the gradients of temperature and moisture content can be neglected. The heat balance for such a particle has the form
Then the drying speed. Hence, it is clear that the greatest influence on the rate of drying is exerted by the particle size.

In fig. 1-2. shows the influence of the parameters of the coolant and the size of the body on the kinetic curve of drying (change in the volume-average moisture content of the material over time).

In the process of conductive drying, the rate of heat supply is determined by the power of the source, the state and size of the heating surface, thermal conductivity of the material, etc., which also affects the intensity of drying. In the case of using energy fields, the drying speed depends on their parameters (frequency, amplitude). 


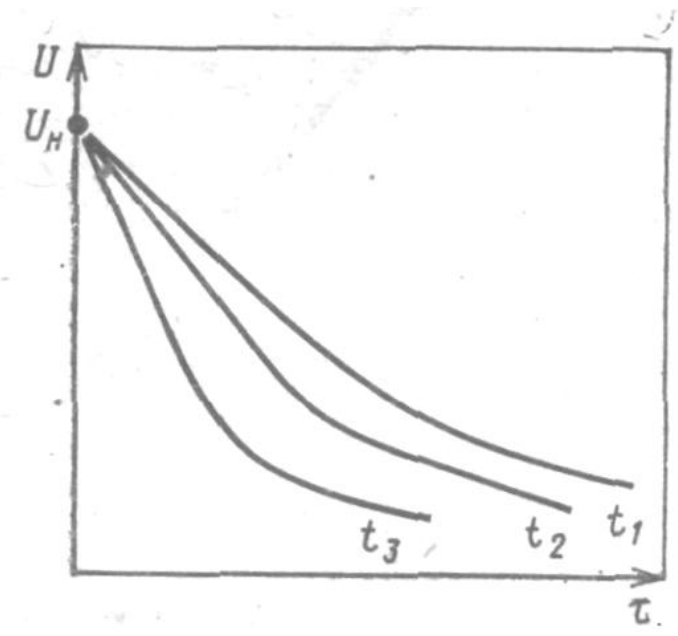

Figure: 1. The nature of the dependence of the kinetic curve of drying on the temperature of the coolant

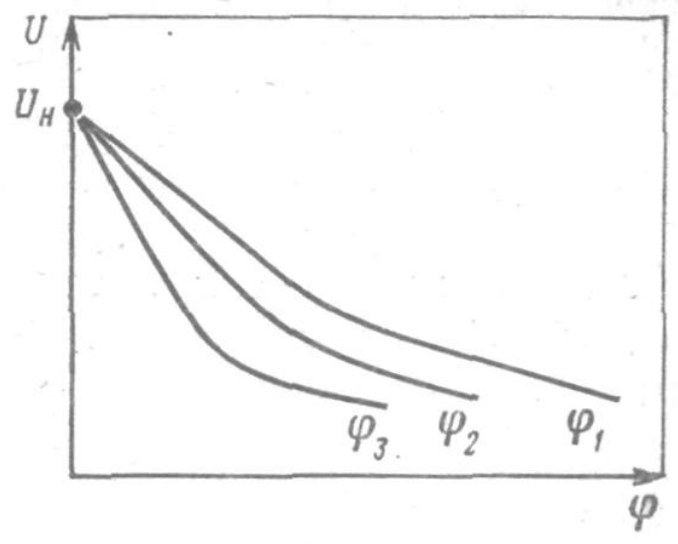

Figure: 2. The nature of the dependence of the kinetic curve of drying on the relative humidity of the coolant

The factors affecting drying include the concentration and composition of impurities contained in the liquid removed from the material. Other substances change the thermophysical properties of the liquid (viscosity, thermal conductivity, etc.), correct the interaction of the liquid with the surface of the solid skeleton, and thereby affect the rate of migration of moisture from the inner layers of the body to the periphery. In the presence of impurities, according to Raoult's law [13], the saturated vapor pressure over the surface of a liquid or a body wetted by it decreases, which leads to a reduction in the moisture flow from the surface of the material to the drying agent.

When drying dispersed materials in a suspended layer apparatus, the drying rate is influenced by the interaction of material particles with each other and with the apparatus wall. When particles hit one another and against the walls of the apparatus, the surface layer is torn off from them, which intensifies drying: the higher the frequency of impacts, the more intense the process proceeds. 


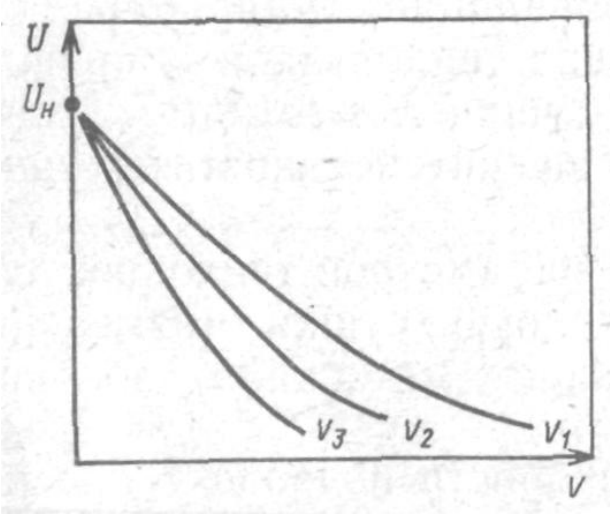

Figure: 3. The nature of the dependence of the kinetic curve of drying on the speed of the coolant

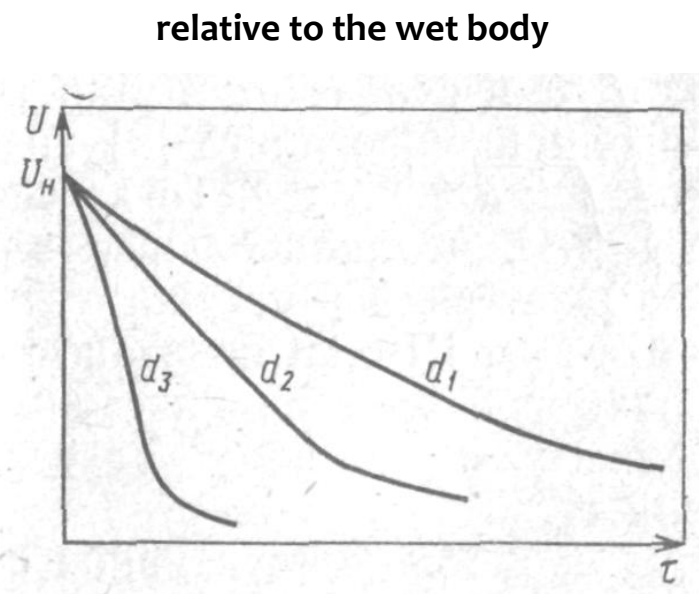

Fig. 4. The nature of the dependence of the kinetic curve of drying on the size of the dried body

From what has been said, it can be concluded that the drying of the material should be intensified by increasing the temperature and speed of the coolant (within the acceptable technology limits), decreasing its initial moisture content, crushing the material (if allowed by technology), using energy fields, etc. However, it must be remembered that with With the intensification of the process, the economic costs of carrying it out also increase, so there is an urgent problem of finding economically optimal conditions for the process.

Thus, the method of mathematical processing ensures the creation of conditions for long-term storage of agricultural raw materials.

\section{CONCLUSION}

To create conditions for long-term storage of agricultural raw materials, it is necessary to use methods of mathematical processing and analysis of experimental results.

\section{REFERENCE}

1. Pento VB, Izotova Al, Golod Bl, Dubiley S.F. "Vitamin powders from fruit and vegetable raw materials." Achievements of science and technology. APK 1990 No. 7, p. 41

2. Allambergenov B. Leveling the uneven moisture content of the drying product // Effective use of energy resources in 
agricultural production: Abstracts. report Rep. scientific. tech. conf.

3. Aminov A.F., Safarov O.F. The process of drying fruits and grapes is heated with ionized air. // J. Storage and processing of agricultural raw materials. 1999 №8.-p. 3941.

4. Artikov A.A., Dodaev K.O., Mamatkulov A.Kh. Mathematical modeling of the process of pneumatic drying of bulk materials. // J. Storage and processing of agricultural products. 1997. No. 2.-P. 32-33.

5. Artikov A.A., Mamatkulov A.Kh., Khamidov N.I. Analysis and synthesis

6. bioheat and mass transfer processes. Tashkent .: Fan. 1994.120p.

7. Ilyina S.A. Experimental determination of the coefficient of thermal diffusivity of vegetables / S.A. Ilyin // Abstract. Cand. diss. Astrakhan. 2006.-22p.

8. Kavetsky G.D. Processes and apparatus of food technology. / G.D. Kavetsky, B.V. Vasiliev.-M .: Kolos, 1997.-551p.

9. Kamovnikov B.P. Atmospheric sublimation drying of food products / B.P. Kamovnikov, A.V. Antipov, G.V. Semenov et al. -M.: Kolos, 1994.-253 p.

10. Korotkaya E.V. Changes in the physicochemical indicators of sea buckthom fruits during freezing / E.V. Korotkaya, I.A. Short. II Storage and processing of agricultural raw materials. - No. 2. - 2006. - p. 35-36.

11. Artikov A.A. and other Electrophysical methods of influencing food products. Tashkent .: Fan of the Academy of Sciences of Uzbekistan. 1992 .-155 p.

12. Artikov A.A., Dzhuraev Kh.F. Methodological aspects of computer modeling of the fruit drying process. /I Mathematical methods in engineering and technology -MMTT-16. Sat. works of HYI
Intern. scientific. conf. T.Z. St. Petersburg. 2003. -from. 129-13p.

13. Gorbatyuk V.I. Processes and devices for food production/V.I. Gorbatyuk. - M .: Kolos, 1999.-335p. 